\title{
EXPERT METHODS OF FOREIGN-LANGUAGE SPEAKERS' IDENTIFICATION BY SPEECH PROSODY
}

\author{
Irina V. Kuryanova \\ Moscow State Linguistic University, Moscow Research Center, Moscow, Russia
}

\begin{abstract}
According to the data received from the surveys of the criminal environment in Russia over recent years, there is a substantial growth of the crimes committed by the Tadjik, Uzbek and criminal groups of other ethnical origin. In forensic phonetics, expert witnesses might be confronted with voice samples for auditory evaluation from a language they do not understand. In speaker identification experiments, it has been shown that knowledge of the target language affects recognition results. The present paper deals with possibility of primary recognition of people speaking foreign language or foreign-accented Russian for the purpose of their further voice identification. This paper also presents one of the automatically-assisted methods of speaker identification i.e. syntagma pitch pattern analysis method (on the ground of pitch pattern segments comparison). There is a brief description of the methodological background and main components of speech melodic structure. The author compares prosodic organization of utterances in speech behaviour of Russian speakers and speakers of foreign languages, and defines the properties of adequate understanding of the meaning of the utterance and of the speaker's communicative goal, including situations when the listener is not a native speaker of the language being used. The results of this study show that (a) experts with experience obtain significantly better recognition results than experts without work experience, (b) no clear evidence was found that the typological difference between the native language of the listener and the target language influenced recognition performance.

Key words: the Tajik language, the Gipsy language, speech interference, foreign speech perception, voice and speech identification, syntagma, melodic patterns of syntagmas, prosodic parameters of speech.

Citation. Kuryanova I.V. Expert Methods of Foreign-Language Speakers' Identification by Speech Prosody. Vestnik Volgogradskogo gosudarstvennogo universiteta. Seriya 2, Yazykoznanie [Science Journal of Volgograd State University. Linguistics], 2018, vol. 17, no. 3, pp. 60-69. (in Russian). DOI: https://doi.org/10.15688/jvolsu2.2018.3.6

\section{ВОЗМОЖНОСТИ ИДЕНТИФИКАЦИИ ИНОЯЗЫЧНЫХ ГОВОРЯЩИХ ПО ГОЛОСУ И РЕЧИ ЭКСПЕРТНЫМИ МЕТОДАМИ}

\author{
Ирина Владимировна Курьянова \\ Московский государственный лингвистический университет, \\ «Московский исследовательский центр», г. Москва, Россия
}

\footnotetext{
Аннотация. Исследование посвящено возможности первичного распознавания говорящих на незнакомом и интерферированном русском языке с целью их дальнейшей идентификации по голосу и речи. В статье рассмотрен один из автоматизированных методов идентификации иноязычных дикторов - метод анализа мелодического контура синтагм (на основе сравнения мелодического оформления различных фрагментов речевого сигнала). Дана краткая характеристика методологической базы, а также охарактеризованы основные компоненты мелодической структуры речи. Автором проведен сопоставительный анализ просодического оформления высказывания в речевом поведении иноязычных дикторов и определены некоторые особенности правильного распознавания говорящего, в том числе со стороны тех, для кого рассматриваемый язык является неродным. В результате исследования установлено, что опытные эксперты способны адекват(2) распознать и правильно идентифицировать иноязычного говорящего. Типологические различия между
} 
родным языком эксперта и языком, подлежащим идентификации, не влияют на правильность распознавания по голосу и речи.

Ключевые слова: таджикский язык, цыганский язык, интерференция, восприятие иноязычной речи, идентификация по голосу и звучащей речи, синтагма, мелодический контур синтагм, просодические параметры речи.

Цитирование. Курьянова И. В. Возможности идентификации иноязычных говорящих по голосу и речи экспертными методами // Вестник Волгоградского государственного университета. Серия 2, Языкознание. 2018. - T. 17, № 3. - C. 60-69. - DOI: https://doi.org/10.15688/jvolsu2.2018.3.6

\section{Введение}

Идентификация иноязычного говорящего экспертом, не являющимся носителем исследуемого языка, представляет собой проблему, разработка которой может быть отнесена к приоритетным направлениям в области судебного речеведения и прикладной лингвистики в целом [Голощапова, 2009, с. 373].

На сегодняшний день судебная экспертиза стала самостоятельным научным направлением. Она имеет в своем распоряжении новые высокотехнологичные способы идентификации личности, в частности, фоноскопическую экспертизу на иностранных языках, которая становится все более востребованной в связи с высокой технической подготовленностью и оснащенностью преступных группировок [Голощапова и др., 2011; 2012]. Как показывает судебная практика, террористическая деятельность националистических, этнических, религиозных и иных организаций и структур, а также преступный бизнес, связанный с незаконным оборотом наркотиков, в настоящее время практически монополизированы этническими (в частности, таджикскими, азербайджанскими, цыганскими, узбекскими и др.) группировками. На Заседании коллегии Федеральной службы безопасности Российской Федерации 5 марта 2018 г. президент России В.В. Путин призвал к созданию «надежных барьеров на пути трансграничной, транснациональной преступности» и подчеркнул, что к приоритетным задачам относится защита нашей территории прежде всего от «международных террористов, контрабандистов и наркодилеров» (стенограмма расширенного заседания коллегии ФСБ России от 05.03.2018).

Идентификация по голосу и речи - сложный многоэтапный процесс, предполагающий интеграцию достижений в различных научных областях (акустике, лингвистике, криминали- стике, психофизиологии, психологии и др.) [Потапова и др., 2015, с. 185]. Исследования по данному вопросу, проводимые за рубежом (в частности, в Германии и Великобритании), основываются на методиках, принятых в этих странах. В частности, в работах О. Кестера и Н. Шиллера рассматриваются проблемы влияния родного языка реципиента при идентификации иноязычного говорящего [Köster, Shiller, 1997; Künzel, 1994; Nolan, 2002]. В отечественной науке первые труды, в которых ставится и разрабатывается данная проблема, включая методики изучения, принадлежат Р.К. Потаповой. Наше исследование посвящено поиску точных, а потому и эффективных методов идентификации говорящих на иностранном языке и опирается на положение о первостепенности просодических средств речи при восприятии высказываний [Потапова, Михайлов, 2012; Потапова, Потапов, 2006 , с. $294 ; 2012$, с. 319 ], в соответствии с которым решается задача выявления ключевых компонентов просодии, позволяющих идентифицировать говорящего на незнакомом эксперту языке.

Чтобы определить возможности первичного опознавания и некоторый объем индивидуальных признаков голоса и речи для успешной идентификации лиц, говорящих на иностранном языке, было проведено исследование, состоящее из двух экспериментов.

\section{Эксперимент 1}

Речевой материал. Материалом для эксперимента послужили аутентичные фонограммы: 14 записей, содержащих спонтанную диалогическую речь (разговор по телефону контрольные фонограммы, $t=57$ мин $28 \mathrm{c}$ ), и 12 записей спонтанной монологической речи (беседа на произвольную тему - опорные фонограммы, $t=8$ ч 19 мин) на таджикском и цы- 
ганском языках, а также на русском языке с признаками интерференции китайского.

Участниками диалогов и монологов являлись этнические таджики и цыгане, говорящие на национальном языке, а также китайцы, говорящие на русском языке, мужчины и женщины в возрасте 35-46 лет, преимущественно со средним (средне-специальным) образованием.

Субъекты. В качестве испытуемых в эксперименте участвовали 46 человек, которые были разделены на 2 группы согласно наличию / отсутствию у них экспертного опыта: в первую были объединены аудиторы-филологи, имеющие опыт экспертной работы, во вторую - включены аудиторы-филологи с отсутсвием такого опыта. Для того, чтобы оценить влияние на степень надежности первичного опознавания не только опыта экспертной работы, но и, по возможности, знания / незнания аудиторами исследуемых языков, в состав реципиентов первой группы наряду с русскоговорящими экспертами, не владеющими таджикским, цыганским и китайским языками, были включены профессиональные эксперты со знанием таджикского языка, а также профессиональные филологи с опытом экспертной работы в области судебной фоноскопии, носители таджикского языка.

Метод. Перцептивно-слуховой анализ фонограмм проводился в соответствии со специально созданной инструкцией, следование которой исключало любые возможные неоднозначные толкования при проведении первого эксперимента. При подготовке инструкции и исследовательских таблиц были использованы образцы анкет и инструкций, разработанных Р.К. Потаповой и В.В. Потаповым при проведении многочисленных экспериментов по восприятию речи [Потапова, Потапов, 2012, с. 324-325]. Наряду с целью первичного опознавания дикторов, испытуемые должны были оценить значимость каждой из анализируемых характеристик при решении поставленной задачи: мелодики, темпоральных и тембральных особенностей, ритма, паузации, высоты голоса.

Pезультатьл. В целом, по результатам эксперимента № 1 могут быть выделены 3 категории ответов: верное опознавание (аудиторы опознают диктора среди опорных фонограмм), ложное отклонение (аудиторы не могут опознать диктора, голос и речь которого представлена на опорных фонограммах), ложное принятие (аудиторы неверно принимают за «своего» один из «чужих» голосов). Кроме того, в процессе прослушивания были зафиксированы случаи неуверенного опознавания (аудиторы опознают диктора среди опорных фонограмм, но сомневаются в правильности своего решения).

В протоколах, подготовленных профессиональными экспертами (группа испытуемых № $1, N=34)$, в $100 \%$ отмечено верное опознавание - не зафиксировано ни одного ошибочного опознавания вне зависимости от языка, на котором говорит диктор. Однако среди верных ответов в $31 \%$ случаев наблюдалось неуверенное опознавание при исследовании экспериментального материала, содержащего эмоционально-насыщенную речь. Для удобства дальнейшей математико-статистической обработки результирующих данных эксперимента первая группа реципиентов была разделена на подгруппы.

В результатах обработки ответов русскоговорящих профессиональных экспертов, не владеющих таджикским и цыганским языками, со стажем экспертной работы от 4 до 10 лет (подгруппа «а», $N=27)$, случаи неуверенного опознавания были представлены следующим образом: речь на таджикском языке - 2,3 \%, на цыганском - 3,7 \% и интерферированном русском $-4,3 \%$.

Содержащие неуверенное опознавание ответы русскоговорящих профессиональных экспертов со знанием таджикского языка, но не владеющих цыганским и китайским, со стажем экспертной работы 5 лет (подгруппа «b», $N=4)$, распределяются следующим образом: таджикский язык - 4,3 \% респондентов, цыганский язык $-2,1 \%$, русский язык с признаками интерференции китайского - 4,4 \%.

У экспертов-носителей таджикского языка со стажем экспертной работы 7 лет (подгруппа «с», $N=3$ ) неуверенное опознавание при идентификации дикторов, говорящих на таджикском языке, не отмечено, на цыганском и русском интерферированном составило $4,3 \%$ и 5,6 \% соответственно.

В протоколах, подготовленных группой испытуемых № 2 (профессиональные филоло- 
ги без опыта экспертной работы, $N=12$ ), представлены следующие категории ответов:

- случаи верного опознавания дикторов, говорящих на таджикском языке, составили $57 \%$ (из них $19 \%$ - неуверенное опознавание, $26 \%$ - ложное отклонение, $17 \%$ ложное принятие);

- случаи верного опознавания дикторов, говорящих на цыганском языке, составили $62 \%$ (из них $21 \%$ - неуверенное опознавание, $27 \%$ - ложное отклонение, $11 \%$ ложное принятие);

- случаи верного опознавания дикторов, говорящих на русском языке с признаками интерференции китайского, составили $68 \%$, из них $12 \%$ - неуверенное опознавание, $10 \%$ - ложное отклонение, $22 \%$ - ложное принятие.

При этом наибольшее количество ошибок (ложное принятие и ложное отклонение) - $56 \%$ - отмечено при исследовании экспериментального материала, содержащего эмоционально-насыщенную речь.

Статистическая обработка ответов испытуемых показала, что различия в точности распознавания между подгруппами первой группы аудиторов было несущественным. Как носители русского языка, владеющие таджикским языком и не владеющие ни одним из иных исследуемых языков, так и носители таджикского языка, не владеющие другими языками (кроме русского), одинаково точно идентифицировали иноязычных дикторов.

Сравнение ответов участников эксперимента групп № 1 и № 2 показало существенные отличия в опознавании иноязычной речи. Аудиторы группы № 2, не имеющие экспертного опыта по перцептивно-слуховому распознаванию голоса и речи, идентифицировали дикторов с контрольных и опорных фонограмм значительно хуже, чем испытуемые, являющиеся профессиональными экспертами. Кроме ложного отклонения и ложного принятия, отмечено большое количество случаев неуверенного опознавания говорящих. Если у группы профессиональных экспертов последнее отмечалось лишь при сопоставлении эмоционально-насыщенной и эмоционально-нейтральной речи, то среди испытуемых группы № 2 отмечены неуверенные ответы при анализе фонограмм, содержащих однотипную по эмоциональной насыщенности речь. При этом статистические данные показали, что не обладающие экспертным опытом аудиторы выполнили задание точнее при сравнении фонограмм, содержащих эмоционально-нейтральную речь.

Исследование экспериментального материала на разных языках характеризуется рядом расхождений при оценке выраженности признаков в зависимости от принадлежности речи диктора конкретному языку.

В группе № 1 наблюдается следующее распределение оценок применительно к анализу используемых для опознавания признаков: таджикский язык - мелодика речи $80 \%$, тембр речи $15 \%$, паузация $5 \%$; цыганский язык мелодика речи $70 \%$, тембр речи $20 \%$, темп речи $3 \%$, паузация $7 \%$; русский язык с признаками интерференции китайского - мелодика речи $60 \%$, тембр речи $22 \%$, паузация $18 \%$.

В группе № 2 оценки распределяются иначе: таджикский язык - мелодика речи $50 \%$, тембр $30 \%$, темп речи $10 \%$, паузация $10 \%$; цыганский язык - тембр речи $40 \%$, мелодика речи $30 \%$, темп речи $15 \%$, громкость голоса $10 \%$, паузация $5 \%$; русский язык с признаками интерференции китайского языка - тембр речи $50 \%$, мелодика речи $30 \%$, паузация $12 \%$, темп речи $8 \%$.

Таким образом, при восприятии иноязычной и интерферированной речи подготовленные эксперты способны уверенно атрибутировать речевые фрагменты по принадлежности определенным дикторам. При этом мелодика речи и сопутствующие воспринимаемые в комплексе признаки играют ведущую роль при первичном опознавании иноязычного говорящего.

Проведенный эксперимент № 1 показал продуктивность работы в этом направлении. Для того, чтобы продолжить предварительное исследование и оценить возможность идентификации иноязычного говорящего по просодическим параметрам голоса методом анализа мелодического контура, был выполнен эксперимент № 2.

\section{Эксперимент 2}

Речевой материал. С учетом вышеописанных результатов для проведения экспери- 
мента № 2 был сформирован обновленный экспериментальный корпус: из речевого материала нами произведена выборка фонограмм, содержащих эмоционально-нейтральную спонтанную диалогическую и монологическую речь на таджикском, цыганском и русском интерферированном языках.

Испытуемым было предоставлено 18 фонограмм, из которых 9 звуковых файлов составили контрольные звукозаписи голоса и речи лиц, говорящих на таджикском, цыганском и интерферированном русском языках $(t=$ 45 мин 35 с), и 9 опорных фонограмм - образцов, предназначенных для сравнительного исследования ( $t=7$ ч 9 мин).

Субъекты. В связи с большим процентом ложного и неуверенного опознавания дикторов непрофессиональными экспертами, a также в соответствии с основной задачей эксперимента № 2 - оценкой возможности успешной идентификации иноязычного говорящего экспертом, не являющимся носителем определяемого языка, - было принято решение об ограничении круга аудиторов, поэтому дипломированные филологи без опыта экспертной работы не привлекались.

В дальнейшем исследовании участвовали профессиональные эксперты $(N=34)$, имеющие право самостоятельного производства экспертиз по специальности «Идентификация по голосу и речи» с разным опытом и стажем экспертной работы, которые для удобства математико-статистической обработки результирующих данных эксперимента были разделены на 2 группы:

- № 1: профессиональные русскоговорящие эксперты, не владеющие рассматриваемыми языками, со стажем экспертной работы 5 лет и более $(N=18)$;

- № 2: профессиональные русскоговорящие эксперты, не владеющие изучаемыми языками, со стажем экспертной работы менее 5 лет $(N=16)$.

Memod. В эксперименте № 2 группам испытуемых предлагалось провести идентификационное сравнение голоса и речи дикторов, говорящих на разных языках, на основе анализа мелодического контура.

С этой целью на базе платформы SIS II универсального акустико-лингвистического комплекса по идентификации дикторов по го- лосу и речи - испытуемым требовалось провести сегментацию реплик говорящего на каждой из предложенных фонограмм, проанализировать индивидуальные характеристики основного голосового тона (кривой ЧОТ) на различных участках и провести сравнительное идентификационное исследование голоса и речи диктора на контрольной и опорной фонограммах на основе сравнения параметров мелодического контура голоса сравниваемых дикторов.

Разработанный метод позволяет эксперту анализировать и сравнивать основные характеристики мелодических структур, представленные как наборы значений параметров частоты основного тона (ЧОТ) для сопоставимых участков мелодического контура (опорных фрагментов).

Для выделенного экспертом фрагмента контура в автоматическом режиме рассчитывались значения начальной, конечной, минимальной, средней и максимальной ЧОТ, время максимума и минимума (координата максимального / минимального значения ЧОТ в процентах от общей длительности выделенного фрагмента), разница между значениями ЧОТ, скорость изменения, коэффициент изрезанности мелодического контура синтагмы, длительность выделенного фрагмента (в мс).

Подбор опорных фрагментов мелодического контура, подлежащих сравнению, осуществлялся испытуемыми на основе аудитивного и визуального анализа речевого сигнала. Такие фрагменты представляли собой синтагмы, а также их структурные составляющие (предшкалы, шкалы, ядерные слоги, ядерно-заядерные участки и т. д. с однотипным мелодическим оформлением).

Для достижения надежного идентификационного решения при сравнении фрагментов аудиторам было рекомендовано соблюдение следующих требований:

1) перед началом сравнительного анализа испытуемые должны были прослушать обе фонограммы, предназначенные для сравнения, и оценить их общую сопоставимость с точки зрения стиля и манеры речи, коммуникативной направленности, эмоциональной окраски;

2) поскольку метод предназначен для сравнения фонограмм без ярко выраженной эмоциональной и модальной окраски, в слу- 
чае необходимости участникам эксперимента следовало удалить из сигнала те участки, которые не соответствуют этому условию;

3) испытуемые должны (по возможности) подобрать элементы контура, имеющие ярко выраженную специфику и несколько примеров реализации в каждой из фонограмм (не менее 5);

4) аудиторы должны провести сравнение голосов в автоматическом режиме.

Параметры выделяемых экспертом на графике основного тона однотипных участков контура, сопоставимых с точки зрения реализационной специфики, коммуникативной и эмоционально-стилистической нагрузки, вычислялись автоматически, данные заносились в таблицу.

Автоматическое сравнение фонограмм осуществлялось на основе полученных средних (пороговых) значений по каждому параметру каждого типа / подтипа элементов мелодического контура. В процессе такого сопоставления для типов / подтипов рассчитывалась степень сходства и различия. Далее результаты сравнения отдельных типов суммировались для получения общего решения относительно тождества либо различия голосов.

При вычислении общего результата учитывались весовые коэффициенты, приписанные каждому параметру и типу фрагмента мелодического контура. Если показатель оценки сходства существенно превышал показатель различий, то вероятность тождества голосов считалась высокой. При высокой степени различий между фонограммами формулировалось решение о различии голосов. При незначительных различиях в оценках (менее $10 \%$ в выдавалось сообщение о невозможности принять решение.

Результаты. Аудиторы группы №1, имеющие опыт экспертной работы более 5 лет, смогли успешно и уверенно выявить сопоставимые сегменты иноязычной речи во всех без исключения случаях. Сегментация сопоставимых фрагментов испытуемыми группы № 2 (опыт работы менее 5 лет) была несколько затруднена в связи с отсутствием навыка восприятия таджикской, цыганской и интерферированной русской речи и потребовала больших временных затрат, однако в целом эту задачу аудиторы также выполнили успешно.
На основе метода анализа мелодического контура аудиторами группы № 1 было установлено 9 лиц, говорящих на таджикском, цыганском и интерферированном русском языках, что составило $100 \%$ от общего количества дикторов, подлежащих идентификации, а испытуемыми группы № $2-7$ лиц, что составило $77,7 \%$.

При анализе идентификационных отчетов, выполненных методом анализа мелодического контура высказываний, обнаружилась прямая зависимость между опытом экспертной работы испытуемого и всесторонностью и правильностью проведенных исследований, в частности, полнотой и точностью выделения типов / подтипов фрагментов контура. Так, аудиторы группы № 1 с высокой степенью точности подобрали и проанализировали опорные фрагменты, дали правильные характеристики типов / подтипов синтагм, достаточно точно зарегистрировали наличие тех или иных речевых особенностей, дали им обоснованное толкование, наиболее полно проанализировали наличие в речи дикторов слов и нефонологических элементов, являющихся заполнителями пауз хезитации. Испытуемыегруппы № 2 также смогли выявить и проанализировать опорные фрагменты синтагмы, однако на выполнение данного задания ими было потрачено существенно больше времени, при этом оценка выявленных признаков затруднений не вызывала.

Таким образом, подготовленные эксперты в спонтанном речевом потоке на таджикском, иызанском и интерферированном русском языках уверенно выявляют и анализируют сопоставимые сегменты в условиях восприятия иноязычной речи. При этом для эффективного использования метода необходимо владеть понятийно-терминологическим аппаратом мелодического анализа и корректно подбирать опорные фрагменты контура для сравнения, соблюдая необходимые условия применимости данного метода.

\section{Заключение}

Результаты эксперимента № 2 позволили установить определенный «инвентарь» просодических характеристик, являющихся информативными при идентификации иноязыч- 
ного диктора. Их статистическая обработка позволила установить следующее.

Диапазон модуляций частоты основного тона в речи дикторов, говорящих на родных таджикском и цыганском языках у́же, чем у дикторов-китайцев, говорящих на интерферированном русском языке.

\section{Распределение типичных значений ЧОТ}

В связи с возможными различиями в особенностях распределения значений ЧОТ внутри каждой языковой группы, обусловленными гендерным фактором, статистической обработке подвергалась только речь дикторов-мужчин.

Область распределения значений ЧОТ различных типов мелодического контура в таджикской речи располагается в диапазоне частот от 125 Гц до 206 Гц. Большинство ядерных слогов сконцентрировано в области значений от 154 Гц до 187 Гц, при этом они по тональному уровню, как правило, не отличаются от обычных ударных слогов (например, в шкалах и предшкалах). Для цыганского языка характерно схожее распределение значений ЧОТ: минимальное и максимальное значения распределились в диапазоне от 102 Гц до 270 Гц, отличие синтагмы ядерных слогов от других ударных также практически не выражено, область значений ЧОТ в ядре синтагмы распределяется от 163 Гц до 207 Гц. При этом в обеих языковых группах очевидна тенденция к функциональному распределению слогов по тональным уровням в зависимости от ударности: чем более значим слог, тем выше уровень распределения значений основного тона голоса и более однозначна его принадлежность к ядерному участку синтагмы.

В группе дикторов-китайцев, говорящих на русском языке, тональный диапазон распределяется в значениях от 88 Гц до 315 Гц, ядерные слоги наиболее часто попадают в диапазон частот от 126 Гц до 292 Гц, при этом другие ударные и безударные слоги реализуются с практически равной частотой основного тона. В качестве дифференцирующего признака ядра испытуемыми отмечалось увеличение силы и (или) громкости произнесения ядерного слога.

Несмотря на то, что количество тональных модуляций у дикторов-китайцев значи- тельно больше, чем у дикторов-таджиков и дикторов-цыган, их речь воспринимается как более однообразная и ровная. Все испытуемые характеризовали китайскую речь как «округло-текучую», с мягкими переходами, вокализованную, эластичную и мелодичную. Речь таджиков и цыган, напротив, характеризуется аудиторами обеих групп как немелодичная, «угловато-отрывистая», с разрывами слов, резкими изменениями громкости.

\section{Особенности паузации}

При анализе особенностей паузации в речи таджиков и цыган, говорящих на родных национальных языках, а также в речи китайцев, говорящих по-русски, наблюдается больше сходств, чем различий. В речи всех указанных языковых групп испытуемые отмечали такие виды пауз, как долгие и короткие по длительности, а также заполненные и незаполненные. Незаполненные паузы зафиксированы в речи во всех исследуемых языках и характеризовались в основном как актуализаторы и (или) способ ограничения фраз без какой-либо дополнительной коннотации; заполненные отмечались испытуемыми гораздо реже и только в случаях хезитации.

Анализ длительности незаполненных пауз показал следующее: короткие незаполненные паузы практически совпадают по длительности в речи на таджикском, цыганском языках и в русской речи китайцев. Длительность коротких незаполненных пауз в речи этнических таджиков составила от 20 мс до 50 мс, цыган - от 15 мс до 40 мс, китайцев - от 25 мс до 60 мс. Длительность долгих пауз имеет следующую область распределения значений: для речи на таджикском языке - 58 мс до 70 мс; на цыганском - от 45 мс до 60 мс; на русском с признаками интерференции китайского - от 63 мс до 80 мс.

Средняя длительность заполненных пауз хезитации в речи таджиков, цыган и китайцев оказалась примерно равной: у дикторов-таджиков от 59 мс до 83 мс, дикторов-цыган от 50 мс до 77 мс, дикторов-китайцев - от 48 мс до 74 мс.

Общее количество коротких по длительности пауз составило примерно 48,4 \% в группе дикторов-таджиков, 39,8 \% в группе дик- 
торов-цыган, 52,3 \% в группе дикторов-китайцев, говорящих на русском языке. Общее количество длинных незаполненных пауз для таджикской, цыганской и интерферированной русской речи в сумме составило $23,6 \%$, $25,3 \%, 27,7 \%$ соответственно.

Заполненные паузы, как было отмечено выше, зафиксированы испытуемыми только в случаях хезитации, по длительности они оценены всеми как длинные. Среднее количество заполненных хезитационных пауз в речи таджиков, цыган и китайцев оказалось практически равным: $12 \%, 14 \%$ и $9 \%$ соответственно.

Основные различия паузации в речи на исследуемых языках наблюдаются в частоте употребления и характере функционирования незаполненных пауз, а также в особенностях заполнения пауз хезитации. Дикторы-таджики и цыгане используют короткие незаполненные паузы для ограничения синтагм (в среднем 69 \% случаев), длинные - как метку-дескриптор, актуализирующую высказывание (в среднем 57 \% случаев). Этнические китайцы, говорящие на русском языке, используют незаполненные короткие и длинные паузы для ограничения синтагм и выделения фраз примерно в равной пропорции, при этом частота их использования выше - в среднем $86 \%$ и $83 \%$ соответственно. Следовательно, зависимость функции паузы от ее длительности у дикторов-китайцев не настолько стабильная, как в речи таджиков и цыган.

Анализ характера заполнения пауз хезитации позволил установить различия в речи дикторов, говорящих на разных языках.

Для дикторов-таджиков характерно заполнение хезитационных пауз растягиванием конечного гласного; [а]-образное, [э]-образное, [эм]-образное заполнение, при этом реализуется одна схема заполнения и употребления таких пауз: «заполнение (100 \% от длительности всей паузы) $\rightarrow$ начало коммуникации». Паузы хезитации встречаются как в начале, так и в середине фразы.

У дикторов-цыган отмечается более разнообразное заполнение пауз хезитации: для них, как и для дикторов-таджиков, характерно [а]-образное, [э]-образное, [эм]-образное заполнение, кроме того частотны случаи заполнения хезитационных пауз причмокиванием, цоканьем, шумным вдохом или выдохом, смехом, скрипящим звуком. Схемы заполнения и употребления пауз также разнообразны, наиболее частотны из них две: «заполнение $(100 \%$ от длительности всей паузы) $\rightarrow$ начало коммуникации»; «заполнение (30-40 \% от длительности всей паузы) $\rightarrow$ молчание (10-20\% от длительности всей паузы) $\rightarrow$ заполнение $(50 \%) \rightarrow$ начало коммуникации».

Для китайцев, говорящих на русском языке, характерно аналогичное дикторам-таджикам заполнение хезитационных пауз: растягивание конечного гласного, а также [эм]-образное заполнение. При этом заполнение пауз растягиванием конечного гласного встречается наиболее часто. Реализуется одна схема заполнения: «заполнение (60-70\% от длительности всей паузы) $\rightarrow$ молчание (30-40 \% от длительности всей паузы) $\rightarrow$ начало коммуникации».

\section{Темпоральные характеристики}

Статистический анализ темпоральных характеристик заключался в исследовании скорости произнесения структурных составляющих синтагмы (предшкал, шкал и ядерных слогов). Особенности темпа речи у представителей исследуемых языковых групп проявляются в скорости произнесения слогов и степени их дифференциации.

В русской речи китайцев ядерный слог практически не отличается по длительности от других ударных и безударных слогов синтагмы в шкале, предшкале и заядерном участке, так как скорость их произнесения очень близка. В речи цыган скорость произнесения ядерного слога приблизительно равна скорости заядерного участка и противопоставлена шкале и предшкале, при этом ударные и безударные слоги шкалы и предшкалы практически не различаются между собой. Дикторытаджики при произнесении ядерных слогов демонстрируют ту же тенденцию, что и дикторы, говорящие на цыганском языке, однако в отличие от речи дикторов-цыган в их речи ударные и безударные слоги шкалы и предшкалы, а также ядерно-заядерный участок более четко дифференцированы.

Среднее значение скоростей произнесения слогов для указанных языков представлено в таблице. 
Среднее значение скорости произнесения слогов (мс)

\begin{tabular}{|l|c|c|c|}
\hline Язык диктора & таджикский & цыганский & $\begin{array}{c}\text { интерферированный } \\
\text { русский }\end{array}$ \\
\cline { 1 - 1 } Исследуемая структура & & 86,05 & 287,06 \\
\hline предшкала (безударный слог) & 268,03 & 90,08 & 307,03 \\
\hline ядерна (ударный слог) & 388,06 & 229,08 & 309,05 \\
\hline заядерный участок & 51,06 & 200,01 & 270,05 \\
\hline
\end{tabular}

В целом, анализируя распределение скоростей произнесения слогов в анализируемом материале, можно констатировать, что для речи китайцев, говорящих на русском интерферированном языке, характерна средняя скорость произнесения слогов, речь таджиков характеризуется как размеренная, речь цыган - как быстрая и очень быстрая по сравнению с речью в других исследуемых языках.

Таким образом, идентификация иноязычных дикторов методами перцептивно-слухового и акустического анализа по просодическим характеристикам голоса и речи позволила выявить определенные закономерности при исследовании просодических параметров, в частности, ритмо-мелодических характеристик, особенностей паузации и темпоральных характеристик голоса и речи.

Результаты экспериментального исследования особенностей восприятия голоса и речи дикторов-таджиков и дикторов-цыган разными аудиторами позволяют говорить о возможности правильной перцептивно-слуховой оценки голоса и иноязычной речи подготовленными экспертами с опытом работы в области криминалистической идентификации по голосу и речи. Корректность восприятия иноязычной речи на супрасегментном уровне зависит от перцептивных эталонов аудиторов (просодических моделей), при этом указанная взаимозависимость уменьшается при наличии опыта в восприятии и анализе сегментов иноязычной речи на слух.

Проведенное экспериментальное исследование подтвердило эффективность применения предлагаемых методов анализа для идентификации русскоязычных и иноязычных дикторов подготовленными экспертами, не владеющими рассматриваемыми языками. Предлагаемый в работе подход к изучению звучащей речи методами анализа мелодических характеристик (перцептивно-слуховой метод) и оценки просодических параметров (ин- струментальный метод анализа параметров ЧОТ на разных мелодических структурах) позволяет обеспечить иеелостный анализ речевого сигнала с акустической (параметры ЧОТ) и лингвистической (интонация, тембр, темп, паузация и т. п.) точек зрения.

\section{СПИСОК ЛИТЕРАТУРЫ}

Голощапова Т. И., 2009. Идентификация иноязычных дикторов автоматическими методами // Информатизация и информационная безопасность правоохранительных органов : материалы междунар. конф. / отв. ред. В. И. Кирин. М. : Академия управления МВД России. C. 372-377.

Голощапова Т. И. и др., 2011. Идентификация по голосу и речи лиц, говорящих на таджикском, узбекском, цыганском и азербайджанском языках, с применением АПК «Этнос» : методические рекомендации для экспертов / Т. И. Голощапова, М. И. Фомичева, И. В. Курьянова, А. В. Малышкин, П. О. Коровянский, Ю. А. Елемешина, Н. А. Фролова / под ред. к.ф.-м.н. С. В. Сыромятникова. 2-е изд., перераб. и доп. М. : ЭКУ 9 Департамента ФСКН России. 155 с.

Голощапова Т. И. и др., 2012. Идентификация иноязычных дикторов на платформе SIS II АПК «Этнос» : методические рекомендации для экспертов / Т. И. Голощапова, Н. А. Кочетов, Ю. А. Елемешина, Е. А. Красовская, М. А. Девятова / под ред. к.ф.-м.н. С. В. Сыромятникова. 3-е изд., перераб. и доп. М. : ЭКУ 9 Департамента Федеральной службы Российской Федерации по контролю за оборотом наркотиков. 142 с.

Потапова Р. К., Михайлов В. Г., 2012. Основы речевой акустики. М. : ИПК МГЛУ «Рема». 493 с.

Потапова Р. К., Потапов В. В., 2006. Язык, речь, личность. М. : Языки славянской культуры. 496 с.

Потапова Р. К., Потапов В. В., 2012. Речевая коммуникация: От звука к высказыванию. М. : Языки славянских культур. 464 с.

Потапова Р. К. и др., 2015. Междисциплинарность в исследовании речевой полиинформативнос- 
ти / Р. К. Потапова, В. В. Потапов, Н. Н. Лебедева, Т. В. Агибалова / под ред. Р. К. Потаповой. М. : Языки славянской культуры. 352 с.

Köster O., Shiller N. O., 1997. Different influences of the native language of a listener on speaker recognition//Forensic Linguistics. The international Journal of Speech language and the law. Vol. 4, no. 1. P. $18-27$.

Künzel H. J., 1994. Current Approaches to Forensic Speaker Recognition' // Proceedings of the ESCA (European Speech Communication Association) Workshop on Automatic Speaker Recognition, Identification and Verification. April 5-7.P. 135-141.

Nolan F., 2002. Intonation in speaker identification: an experiment on pitch alignment features // Forensic Linguistics. The international Journal of Speech language and the law. Vol. 9, no. 1. P. 1-21.

\section{REFERENCES}

Goloshchapova T.I., 2009. Identification of foreign speakers by automatic methods. Kirin V.I. (ed). Informatizatsiya i informatsionnaya bezopasnost pravookhranitelnykh organov: Materialy mezhdunar. konf. Moscow, Akademiya upravleniya MVD Rossii Publ., pp. 372-377.

Goloshchapova T.I., Fomicheva M.I., Kuryanova I.V., MalyshkinA.V., KorovyanskiyP.O.,Elemeshina Yu.A., Frolova N.A., 2011. Identification of speakers of Tajik, Uzbek, Gypsy and Azerbaijani languages by voice and speech with the use of the hardware-software complex 'Etnos': Methodological recommendations for experts.
Moscow, EKU 9 Departamenta FSKN Rossii. $155 \mathrm{p}$.

Goloshchapova T.I., Kochetov N.A., Elemeshina Yu.A., Krasovskaya E.A., Devyatova M.A., 2012. Voice identification of foreign speakers on the platform SIS II of the hardware-software complex 'Etnos': Methodological recommendations for experts. Moscow, EKU 9 Departamenta FSKN Rossii. 142 p.

Potapova R.K., Mikhaylov V.G., 2012. Bases of speech acoustics. Moscow, Rema Publ. 493 p.

Potapova R.K., Potapov V.V., 2006. Language, speech, personality. Moscow, Yazyki slavyanskikh kultur Publ. 496 p.

Potapova R.K., Potapov V.V., 2012. Speech communication: from sound to utterance. Moscow, Yazyki slavyanskikh kultur Publ. 464 p.

Potapova R.K., Potapov V.V., Lebedeva N.N., Agibalova T.V., 2015. Interdisciplinarity in the study of speech poly-informativity. Moscow, Yazyki slavyanskikh kultur Publ. 352 p.

Köster O., Shiller N.O., 1997. Different influences of the native language of a listener on speaker recognition. Forensic Linguistics. The international Journal of Speech language and the law, vol. 4, no. 1, pp. 18-27.

Künzel H.J., 1994. Current Approaches to Forensic Speaker Recognition. Proceedings of the ESCA (European Speech Communication Association). Workshop on Automatic Speaker Recognition, Identification and Verification, April 5-7,pp. 135-141.

Nolan F., 2002. Intonation in speaker identification: an experiment on pitch alignment features. Forensic Linguistics. The international Journal of Speech language and the law, vol. 9, no. 1, pp. 1-21.

\section{Information about the Author}

Irina V. Kuryanova, Postgraduate Student, Department of Applied and Experimental Linguistics, Institute of Applied and Mathematical Linguistics, Moscow State Linguistic University, Ostozhenka St., 38, bld. 1, 119034 Moscow, Russia; Deputy Head of Department of Linguistic Expertise and Research, Moscow Department of Regional Security and Anti-Corruption Activity, Moscow Research Center, Nizhnyaya Syromyatnicheskaya St., 5, bld. 3, 105120 Moscow, Russia, ivkuryanova@mail.ru, https://orcid.org/0000-0003-3698-3013

\section{Информация об авторе}

Ирина Владимировна Курьянова, соискатель кафедры прикладной и экспериментальной лингвистики, Институт прикладной и математической лингвистики, Московский государственный лингвистический университет, ул. Остоженка, 38, стр. 1, 119034 г. Москва, Россия; заместитель начальника отдела лингвистических экспертиз и исследований департамента региональной безопасности и противодействия коррупции г. Москвы, государственное бюджетное учреждение г. Москвы «Московский исследовательский центр», ул. Нижняя Сыромятническая, 5, стр. 3, 105120 г. Москва, Россия, ivkuryanova@mail.ru, https://orcid.org/0000-0003-3698-3013 